\title{
Current Colorectal Cancer in Thailand
}

\author{
Varut Lohsiriwat ${ }^{1}$, Nopdanai Chaisomboon ${ }^{2}$, Jirawat Pattana-Arun ${ }^{3}$; for the Society of Colorectal Surgeons \\ of Thailand
}

${ }^{1}$ Department of Surgery, Faculty of Medicine Siriraj Hospital, Mahidol University, Bangkok; ${ }^{2}$ Department of Surgery, Bhumibol Adulyadej Hospital, Bangkok; ${ }^{3}$ Department of Surgery, King Chulalongkorn Memorial Hospital, Chulalongkorn University, Bangkok, Thailand

This article aimed to summarize the current status of colorectal cancer (CRC) in Thailand. In brief, CRC is the third most common cancer and accounts for $11 \%$ of the cancer burden in Thailand. It is the only malignancy with an increased incidence in both sexes in Thailand. Over 10,000 new CRC cases occur annually, and about $40 \%$ are rectal cancer. Due to the lack of CRC screening and public awareness, nonmetastatic cancer accounts only for $60 \%-70 \%$ of overall cases. The demand for general or colorectal surgeons outmatches the supply at a ratio of 1 general surgeon to 35,000 individuals. There are about 70 board-certified colorectal surgeons serving Thailand's population of nearly 70 million. As a result, $>25 \%$ of cancer patients wait more than 1 month before surgery. Regarding training for colorectal surgery, there are 3 major institutes in Bangkok providing a 2-year fellowship program. Cadaveric workshops are an important part of training - especially in laparoscopy for CRC. Recently, a population-based CRC screening program was launched using a fecal immunochemical test. The Ministry of Public Health of Thailand has established additional platforms for laparoscopy to support the potential detection of early CRC following implementation of this nationwide screening program.

Keywords: Colonic neoplasms; Rectal neoplasms; Surgery; Screening; Thailand

\section{INTRODUCTION}

The incidence of colorectal cancer (CRC) has been increasing in developing countries worldwide, including Thailand [1]. In Thailand, CRC remains a major unsolved healthcare burden for several reasons: (1) population-based CRC screening programs are lacking and difficult to organize, (2) the national CRC registry suffers from quality control issues, (3) there are limited budgets and few highly qualified healthcare providers to deal with CRC patients with either curative intention or palliative care, and (4) more advanced treatment approaches and facilities involving minimally invasive surgery (MIS), chemotherapy, and radiation are limited to referral university hospitals or cancer institutes. The

Received: 24 November 2019 - Accepted: 7 January 2020

Correspondence to: Varut Lohsiriwat M.D.

Department of Surgery, Faculty of Medicine Siriraj Hospital, Mahidol

University, 2 Wang Lung Road, Bangkok 10700, Thailand

Tel: +66-2-4198005, Fax: +66-2-4121370

E-mail: bolloon@hotmail.com

ORCID: https://orcid.org/0000-0002-2252-9509

(C) 2020 The Korean Society of Coloproctology

This is an open-access article distributed under the terms of the Creative Commons Attribution NonCommercial License (https://creativecommons.org/licenses/by-nc/4.0) which permits unrestricted noncommercial use, distribution, and reproduction in any medium, provided the original work is properly cited. present article aims to provide an overview of the current status of CRC in Thailand in terms of screening, fundamental treatment, and policy strategies to address the challenges described above.

\section{INCIDENCE AND STAGING OF COLORECTAL CANCER IN THAILAND}

From 2000 to 2012, CRC was the only malignancy in Thailand with an increased incidence in both sexes (average annual percent changes in males $=4.1 \%$ and in females $=3.1 \%$ ) regardless of geographic region [2]. Currently, CRC is the third leading cancer in males and the fourth most common cancer in females. In 2018, 17,534 new CRC cases were detected and accounted for $10.3 \%$ of all new cancer cases in Thailand [1]. The age-standardized rates of CRC in Thailand as reported by the National Cancer Institute in 2018 were $16.2 / 100,000$ men and $11.2 / 100,000$ women [3]. In term of age, the incidence of CRC was highest in the 60- to 75-year-old age group (about 50\% of CRC cases). Interestingly, rectal malignancy accounts for about $40 \%$ of all CRC in Thailand [3]. Many patients with rectal cancer are referred to tertiary university hospitals or regional cancer institutes for appropriate multidisciplinary approaches [4], while patients with colon cancer are treated in primary and secondary hospitals. 
In Thailand, the incidence of cancer staging in patients with newly diagnosed CRC is $4 \%-9 \%$ for stage I, $17 \%-22 \%$ for stage II, $31 \%-37 \%$ for stage III, and $32 \%-40 \%$ for stage IV $[4,5]$.

Due to lack of organized population-based CRC screening and public awareness, stage I and II CRC accounts only for $20 \%-30 \%$ of overall CRC cases in Thailand, while the majority of patients have nodal and/or distant metastases. Approximately one-quarter of patients with rectal cancer have a permanent colostomy [6]. About $12 \%$ of CRC patients present with acute colonic obstruction with or without concomitant bowel perforation [7].

Notably, there are 3 major government-based healthcare schemes in Thailand: universal coverage (covering roughly $75 \%$ of the Thai population), social security (covering about $15 \%$ of the Thai population), and the healthcare scheme for government officers (covering $10 \%$ of the Thai population). All necessary investigations and open surgery are fully reimbursed in every government-based healthcare scheme using the Thai diagnosis-related group system for prospective payment of inpatient care, while laparoscopy is only partially covered.

\section{WAITING TIME FOR SURGERY AND NUMBER OF SURGEONS}

Similar to other countries, surgery remains the mainstay of CRC treatment in Thailand for both curative resection and palliative purposes. Based on the database of the Department of Medical Services, Ministry of Public Health of Thailand in July 2019, there are about 2,000 board-certified general surgeons to provide surgical services for Thailand's population of almost 70 million-equivalent to roughly 1 general surgeon per 35,000 people. Notably, many surgeons work in the private sector and university-based hospitals, leaving about half of Thai board-certified general surgeons in government-based hospitals. At the time of manuscript preparation, 83 board-certified colorectal surgeons were alive in Thailand, but only 69 were currently practicing, with 59 in the public sector, including 28 in university hospitals. As a result, over one-quarter of cancer patients have to wait more than one month to start treatment (unpublished data), although the Ministry of Public Health of Thailand seeks to schedule an operation for cancer patients within 4 weeks after completion of clinical or radiological staging.

\section{GROWTH OF MINIMALLY INVASIVE SURGERY FOR COLORECTAL CANCER IN THAILAND}

The expanded use of MIS (either laparoscopy or hand-assisted laparoscopy) for CRC in Thailand can be traced back to the early 2000 s - mainly in major university hospitals $[8,9]$. Although laparoscopy is associated with low morbidity and shorter convalescence, a nationwide survey of Thai colorectal surgeons in 2009 found that only $40 \%$ of surgeons had performed laparoscopic proctectomy for rectal cancer due to the uncertainty of its oncological outcomes [10]. Over the last 10 years, there has been increasing evidence suggesting that there are no significant differences in oncological outcomes between laparoscopy and an open approach to rectal cancer [11]. Accordingly, many Thai surgeons have increasingly performed MIS for colon and rectal malignancies, although the majority of laparoscopy for CRC is still practiced in high-volume hospitals by board-certified colorectal surgeons or well-trained laparoscopic surgeons. The total number of major operations for CRC and the percentage of laparoscopic surgery for CRC performed in some university hospitals in Thailand from 2017 to 2018 are shown in Fig. 1. From a nationwide perspective, however, there are several reasons for the slow adoption of laparoscopic surgery for CRC, including lack of well-trained laparoscopic surgeons, long learning curve, unsuitable cases (e.g., bulky tumor or locally advanced cancer), suboptimal laparoscopic equipment, and absence of reimbursement for some instruments used in laparoscopy.

\section{ROLES OF THE SOCIETY OF COLORECTAL SURGEONS OF THAILAND IN ACADEMIC TRAINING}

The Society of Colorectal Surgeons of Thailand was established in 1977 and was recognized as the first surgical subspecialty in Thailand. A 2-year training program for colorectal surgery has been approved by the Royal College of Surgeons of Thailand and the Medical Council of Thailand for over 20 years. Certification in general surgery is a prerequisite for training in colorectal surgery. In Thailand, a 4-year residency training program for general surgeons covers colonoscopy and oncological/palliative surgery for CRC. According to the World Federation of Medical Education Global Standards, candidates for Thai board-certified general surgeons need to participate in direct observation for procedural skill for at least 5 colonoscopies, 3 colectomies, and 1 proctectomy. Meanwhile, along with formal board examination, candidates for Thai board-certified colorectal surgeon are required to have experience as a competent primary surgeon for at least 100 colonoscopies, 20 colectomies, and 14 proctectomies.

To date, there are only 3 training centers for colorectal surgeons in Thailand: King Chulalongkorn Memorial Hospital (2 positions), Faculty of Medicine Siriraj Hospital (2 positions), and Rajavithi Hospital (1 position). Of note, all training centers are located in Bangkok. However, the demand for highly qualified colorectal surgeons outmatches the supply, because there are approximately 70 active board-certified colorectal surgeons to serve the whole country with a population of 70 million people. It is, thus, a concern what academic society can do to improve treatment of CRC.

Increasing the number of training centers for colorectal surgery is a viable option but not a simple task; each institute must meet specific requirements to be accepted as a training center. For ex- 


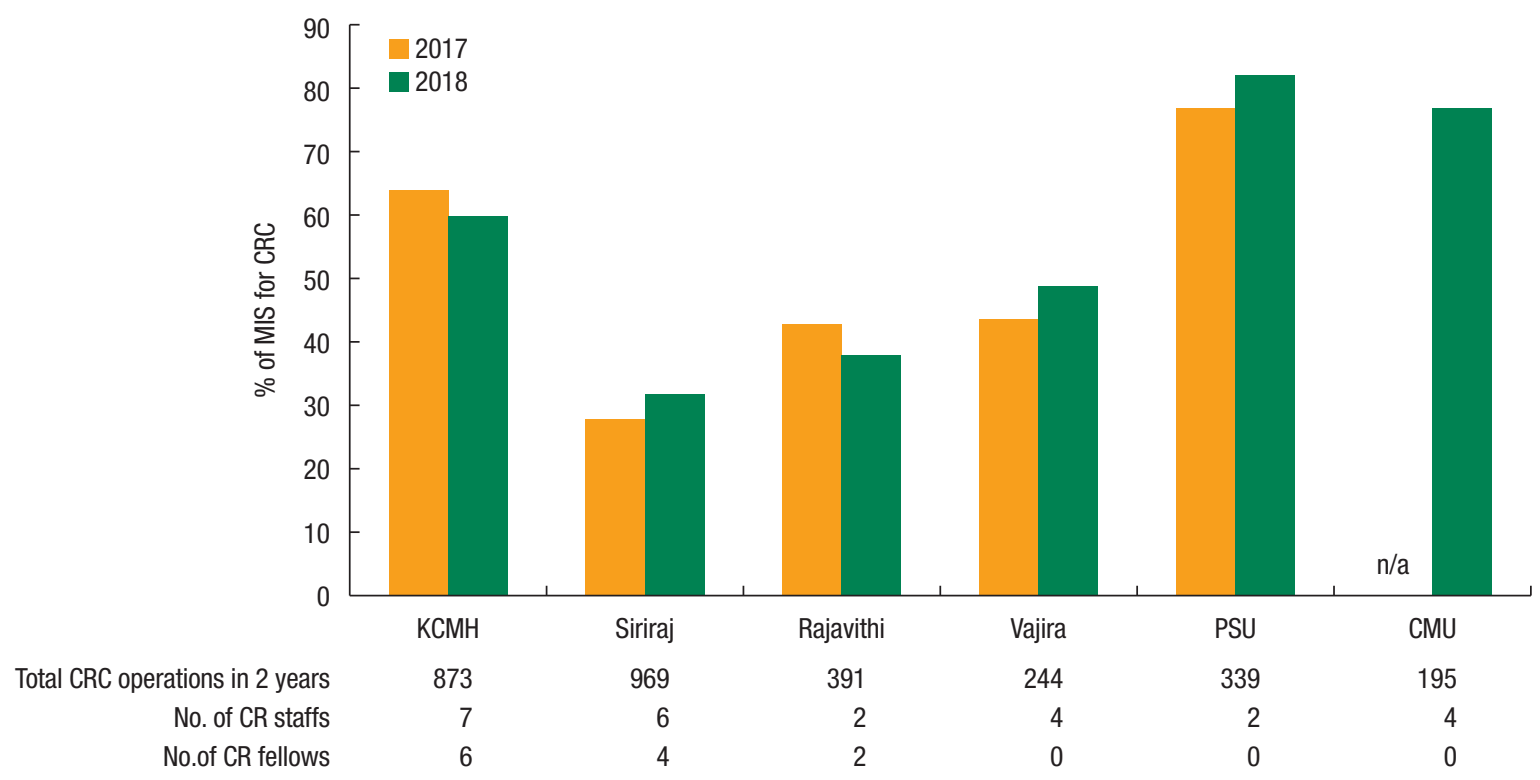

Fig. 1. Total number of major operations and percentage of laparoscopies for colorectal cancer performed in 6 major university hospitals in Thailand from 2017 to 2018. MIS, minimally invasive surgery; CRC, colorectal cancer; CR, colorectal; KCMH, King Chulalongkorn Memorial Hospital; PSU, Prince of Songkla University; CMU, Chiang Mai University; n/a, no available data.

ample, training centers are required to have at least 2 board-certified colorectal surgeons per trainee and at least 400 colorectal operations per annum. Improvements in teaching and practice of oncological surgery for CRC during the four-year residency program of general surgery might offer a better method of achievement, along with a postgraduate training course focusing on practical points and surgical aspects of CRC management.

Cadavers and their related workshops are an integral and important part of surgical training because they provide a meaningful simulation before encountering surgical patients - especially for MIS for CRC [12]. Established for more than 10 years, the Chula Soft Cadaver Surgical Training Center and Siriraj Training and Education Center for Clinical Skills are the 2 most wellknown cadaveric training centers in Thailand. At least 5 cadaveric hand-on workshops on basic and advanced colorectal operations (either open or laparoscopic approach) are held annually among the 2 training centers. Recently, another cadaveric training center was opened outside Bangkok by Maharaj Nakorn Chiang Mai Hospital.

\section{WHAT WE HAVE DONE NATIONALLY}

Since CRC is one of the leading causes of cancer deaths in Thailand, the Thai Government in cooperation with the Ministry of Public Health and the National Cancer Institute of Thailand recently has paid more attention to primary and secondary prevention to control CRC. Based on a survey of current practice in CRC screening and surveillance among Thai general surgeons in 2009 [13], fecal occult blood testing and colonoscopy were the 2 most popular investigations used for CRC screening in the asymptomatic, average-risk population. Most clinicians started CRC screening in individuals at the age of 50 years and did not screen populations older than 80 years. After curative CRC resection, most surgeons set up a surveillance program every 3 months in the first 2 years and performed post-CRC resection colonoscopic surveillance at 1 year and every 3-5 years thereafter [13].

A nationwide Thailand CRC screening program was launched in October 2017, for asymptomatic participants aged 50-70 years, using a one-time quantitative fecal immunochemical test (FIT). The estimated population to be screened was 13.3 million, and the pilot project covered 1.2 million people in the first year. The initial cutoff level of FIT was $100 \mathrm{ng} / \mathrm{mL}$, and FIT-positive individuals were invited to undergo colonoscopy. However, after a preliminary analysis, it was suggested that the optimal cutoff level of FIT for CRC screening in Thailand be $150 \mathrm{ng} / \mathrm{mL}$, because it offered both high positive and negative predictive values for advanced neoplasia detection and reduced colonoscopy workload without increasing the rate of missed CRC [14]. It is estimated that, if the entire targeted population of Thailand was enrolled in the FIT-based CRC screening program with a $70 \%$ participation rate, approximately 100,000 individuals would have a positive FIT and require colonoscopy [15]. A pilot implementation program in the north region of Thailand found that $72 \%$ of FIT-positive individuals eventually underwent colonoscopy, revealing CRC in $3.7 \%$ and adenoma in $30.6 \%$ [16].

It is noteworthy that endoscopic units and colonoscopy resources are quite limited in Thailand, as is the number of boardcertified endoscopists (about 250 gastroenterologists and 70 
colorectal surgeons). Fortunately, many general surgeons in Thailand are capable of performing diagnostic and therapeutic colonoscopy because of the inclusion since 2000 of fundamentals in endoscopy in the 4-year residency training curriculum.

Although a reduction in CRC-related mortality has not been noted, our government has established another 2 surgical programs to support potential detection of early CRC following implementation of the nationwide CRC screening program: one-day surgery (ODS) starting in January 2018 and MIS for CRC starting in January 2020. These 2 service platforms will provide patients with better and safer services, decreased waiting time and overcrowding in hospitals, as well as reduced healthcare costs.

Initially, the Ministry of Public Health of Thailand aims to set up at least one healthcare unit (provincial hospital - excluding university hospitals and regional cancer institutes) with complete ODS and MIS platforms in each regional health area of Thailand (13 regions including Bangkok metropolitan) by 2021. Although the MIS platform for CRC in Thailand will cover laparoscopic colectomy, laparoscopic anterior resection, laparoscopic total mesorectal excision, and laparoscopic abdominoperineal resection, this program will start off with laparoscopic colectomy, which is supported and reimbursed by Thailand's universal healthcare coverage scheme.

\section{CONCLUSION}

The incidence of CRC in Thailand has continued to increase in both sexes. A qualified and complete nationwide registry of CRC is much needed. The cancer registry will help us not only understand the characteristics of CRC in individuals, but also contribute to their treatment, as well as research and national health policies for primary and secondary prevention of CRC. As surgery remains the mainstay of CRC treatment in Thailand, the number of highly qualified general surgeons and board-certified colorectal surgeons needs to increase to match the volume of CRC cases. Meanwhile, multidisciplinary approaches to CRC will result in better clinical outcomes and patient quality of life. For the first time, the Ministry of Public Health of Thailand launched a population-based CRC screening program in late 2017, and prepared a nationwide surgical platform of laparoscopy for CRC to support potential detection of early CRC following implementation of the CRC screening program - with an ultimate goal of reducing the incidence of CRC and CRC-related mortality in Thailand.

\section{CONFLICT OF INTEREST}

No potential conflict of interest relevant to this article was reported.

\section{REFERENCES}

1. Bray F, Ferlay J, Soerjomataram I, Siegel RL, Torre LA, Jemal A.
Global cancer statistics 2018: GLOBOCAN estimates of incidence and mortality worldwide for 36 cancers in 185 countries. CA Cancer J Clin 2018;68:394-424.

2. Virani S, Bilheem S, Chansaard W, Chitapanarux I, Daoprasert K, Khuanchana S, et al. National and subnational population-based incidence of cancer in Thailand: assessing cancers with the highest burdens. Cancers (Basel) 2017;9(8). pii: E108. https://doi. org/10.3390/cancers 9080108 .

3. Imsamran W, Pattatang A, Supaattagorn P, Chiawiriyabunya I, Namthaisong K, Suwanrungruang K, et al. Cancer in Thailand: Vol. IX, 2013-2015. Bangkok (Thailand): New Thammada Press; 2018.

4. Techawathanawanna S, Nimmannit A, Akewanlop C. Clinical characteristics and disease outcome of UICC stages I-III colorectal cancer patients at Siriraj Hospital. J Med Assoc Thai 2012;95 Suppl 2:S189-98.

5. National Cancer Institute of Thailand. Hospital-based cancer registry 2017. Bangkok (Thailand): Pronsup Printing; 2017.

6. Lohsiriwat V, Lohsiriwat D, Boonnuch W, Chinswangwatanakul V, Akaraviputh T, Lert-Akayamanee N. Pre-operative hypoalbuminemia is a major risk factor for postoperative complications following rectal cancer surgery. World J Gastroenterol 2008;14:124851.

7. Lohsiriwat V. Enhanced recovery after surgery vs conventional care in emergency colorectal surgery. World J Gastroenterol 2014; 20:13950-5.

8. Sahakitrungruang C, Pattana-arun J, Tantiphlachiva K, Rojanasakul A. Laparoscopic versus open surgery for rectosigmoid and rectal cancer. J Med Assoc Thai 2005;88 Suppl 4:S59-64.

9. Lohsiriwat V, Lohsiriwat D, Chinswangwatanakul V, Akaraviputh T, Lert-Akyamanee N. Comparison of short-term outcomes between laparoscopically-assisted vs. transverse-incision open right hemicolectomy for right-sided colon cancer: a retrospective study. World J Surg Oncol 2007;5:49.

10. Lohsiriwat $\mathrm{V}$, Lohsiriwat $\mathrm{D}$, Thavichaigarn P. Current practices in rectal cancer surgery: a survey of Thai colorectal surgeons. J Med Assoc Thai 2009;92:1009-15.

11. Chen K, Cao G, Chen B, Wang M, Xu X, Cai W, et al. Laparoscopic versus open surgery for rectal cancer: a meta-analysis of classic randomized controlled trials and high-quality Nonrandomized Studies in the last 5 years. Int J Surg 2017;39:1-10.

12. Pattana-arun J, Udomsawaengsup S, Sahakitrungruang C, Tansatit T, Tantiphlachiva K, Rojanasakul A. The new laparoscopic proctocolectomy training (in soft cadaver). J Med Assoc Thai 2005;88 Suppl 4:S65-9.

13. Lohsiriwat V, Lohsiriwat D, Thavichaigarn P; Society of Colon and Rectal Surgeons Thailand. Colorectal cancer screening and surveillance: a survey among Thai general surgeons. Asian Pac J Cancer Prev 2009;10:467-70.

14. Aniwan S, Ratanachu Ek T, Pongprasobchai S, Limsrivilai J, Praisontarangkul OA, Pisespongsa P, et al. The optimal cut-off level of the fecal immunochemical test for colorectal cancer screening 


\section{Coloproctology Varut Lohsirimat, et al.}

in a country with limited colonoscopy resources: a multi-center study from Thailand. Asian Pac J Cancer Prev 2017;18:405-12.

15. Saengow U, Chongsuwiwatvong V, Geater A, Birch S. Preferences and acceptance of colorectal cancer screening in Thailand. Asian Pac J Cancer Prev 2015;16:2269-76.
16. Khuhaprema T, Sangrajrang S, Lalitwongsa S, Chokvanitphong V, Raunroadroong T, Ratanachu-Ek T, et al. Organised colorectal cancer screening in Lampang Province, Thailand: preliminary results from a pilot implementation programme. BMJ Open 2014; 4:e003671. 